\title{
Marshall and Rotterdam Computed Tomography scores in predicting early deaths after brain trauma
}

\author{
Mahyar Mohammadifard (1), Kazem Ghaemi (2), Hamed Hanif (3), Gholamreza Sharifzadeh \\ (4), Marzieh Haghparast (5)
}

(1) Department of Radiology, Imam Reza Hospital, Birjand University of Medical Sciences, Birjand; (2) Department of Neurosurgery, Birjand University of Medical Science, Birjand; (3) Department of Neurosurgery, Sina Hospital, Tehran University of Medical Sciences (TUMS), Tehran; (4) Birjand Infectious Diseases Research Center, Assistant Professor of Epidemiology, Birjand University of Medical Sciences, Birjand; (5) Department of Radiology, Birjand University of Medical Sciences, Birjand, Iran

This article is distributed under the terms of the Creative Commons Attribution Noncommercial License (CC BY-NC 4.0) which permits any noncommercial use, distribution, and reproduction in any medium, provided the original author(s) and source are credited.

\begin{abstract}
Trauma is one of the most important issues of most healthcare systems accompanying with head trauma in the most cases. We sought to determine the scoring system and initial Computed Tomography (CT) findings predicting the death at hospital discharge (early death) in patients with traumatic brain injury based on Marshall and Rotterdam CT scores. This is a cross sectional study on traumatic neurosurgical patients with mild-to-severe traumatic brain injury admitted to the emergency department of Emam Reza Hospital, Birjand University of Medical Sciences. Patients $\geq 18$ years old with TBI during last 24 hours with GCS $\leq 13$ were included and exclusion criteria were multiple trauma, penetrating injuries, previous history of anticoagulant therapy, pregnancy, not willingness for participation. Their initial CT and status at hospital discharge, one and three months (dead or alive) were reviewed, and both CT scores were calculated. We examined whether each score is related to death using SPSS11 by The Mann-Whitney U at the level of $\mathrm{p} \leq 0.05$. Overall, 98 patients were included. Mean age was $43.52 \pm 21.29$. Most patients

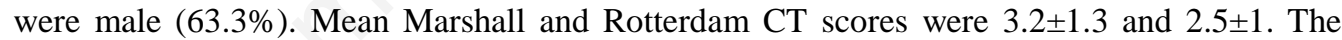
mortality at two weeks, one moth and three months were $19.4 \%, 20.4 \%$, and $20.4 \%$. Rotterdam CT score was significantly different based on type of hematoma. Median GCS score in alive and dead patients on 2 weeks were 10 and $4(\mathrm{p}=0.0001)$, at one month were 10 and $4(\mathrm{p}=0.0001)$, and at three months were 10 and $4(\mathrm{p}=0.0001)$. The median Marshall CT score on 2 weeks were 2 and $4(\mathrm{p}=0.0001)$, at one month were 2 and $4(\mathrm{p}=0.0001)$, and at three months were 2 and 4 $(\mathrm{p}=0.0001)$. The median Rotterdam CT score on 2 weeks were 2 and $4(\mathrm{p}=0.0001)$, at one month were 2 and $3(p=0.001)$, and at three months were 2 and $3(p=0.001)$. The Rotterdam CT score was significantly correlated with mortality at two weeks, one month and three months $(\mathrm{p}=0.004$, $\mathrm{p}=0.001$, and $\mathrm{p}=0.001$, respectively). The Marshall CT score was not significantly correlated with mortality at any time. The Rotterdam CT score was more accurate for prediction of mortality on 2 weeks (ROC80.9), at one month (ROC80.7), and at three months were (ROC80.7) than The Rotterdam CT score (ROC 76, 74.1, and 74.1, respectively). This study concluded that The Marshall CT score was more accurate for prediction of mortality on 2 weeks, at one month, and at three months were than The Marshall CT score with higher ROC. The correlation of the Rotterdam CT score with mortality was significant.
\end{abstract}

Key Words: Marshall scores, Rotterdam scores, brain CT scan, head trauma

Eur J Transl Myol 28 (3): 265-273, 2018

Trauma is one of the most important health care problems in most countries of the world, which can be caused by traffic accidents, falls, violent acts, injuries and occupational injuries. Trauma refers to severe traumatic injuries that occur in the event of an accident. ${ }^{1,2}$ In patients with historyoftraumatic events, targeted physical examination and evaluation of patient transmission are important. Exact evaluation of the likely mechanism of 


\section{Marshall and Rotterdam CT scores}

Eur J Transl Myol 28 (3): 265-273, 2018

the trauma or type of illness, along with obtaining other information, will be lead to better treatment. ${ }^{1,2}$ Trauma is usually divided into two blunt trauma and penetrating trauma. In blunt trauma, the force is spread over a wide area of the body, and skin does not suffer serious damage, while the organs and underlying tissues may be injured at the site of the force. In penetrating trauma, force enters a tissue of the body, causing an open wound with a high infection risk. ${ }^{1,2}$ Traumatic brain injury (TBI) has the highest mortality rate. ithas been found that TBI is a major cause of death that were 3 times more likely than other trauma patients. ${ }^{1}$ Each year more than one million trauma visits occur in the United States due to TBI, of which $10 \%$ are moderately damaged $(\mathrm{GCS}=9-13)^{2}$ TBI is associated with significant morbidity and mortality and is one of the main causes of death due to accidents. ${ }^{3}$ On the other hand, mortality from severe head injury has decreased from $50 \%$ to $30 \%$ over the past three decades without increasing the serious neurological complications. The reason for this issue is mainly due to increased knowledge about the pathophysiology of TBI and the improvement in special care and treatment of these patients. ${ }^{4}$ Since brain injury is one of the leading causes of death worldwide, prediction of outcome at the time of admission is difficult for clinical decisionmaking, resource allocation and family counseling for patients. ${ }^{5}$ Computed tomography currently plays an important role in the rapid assessment of post-traumatic hemorrhagic lesions in patients with brain injury, so that the patient's need for emergency neuropsychiatric surgery is diagnosed. There are two scoring systems to predict the outcomes in patients with brain injury on the basis of Computed Tomography (CT) results. The Marshall System (1991) and the Rotterdam CT score of TBI (2005) aimed at improving patient outcomes prediction. ${ }^{6,7}$ The Marshall classification of TBI is a good predictor and is very popular with some limitations. One of the important limitations of this system is the division of the hematoma into evacuated or non-evacuated. The second problem is separation of mass lesion volume at 25 cc. Due to the existence of different clinical guidelines, surgery for brain damage and various cut off plans do not seem logical. Epidural hematoma (EDH) mortality is 7 to $12.5 \%$, subdural hematoma (SDH) is $40-60 \%$, and Contusions is $16-72 \%$. Both scoring systems have been widely used to represent demographic issues, ${ }^{8}$ or independent predictors of outcomes. 9 However, few studies have evaluated the performance of both systems. Except for the study of Mata-Mbemba,${ }^{5}$ other studies also reported that Rotterdam's score was better than Marshall. ${ }^{9}$ Therefore, this study was conducted to compare the predictive power of the two methods.

\section{Materials and Methods}

\section{Ethical considerations}

Written informed consent was obtained from all patients. All emergency procedures were performed by emergency specialists and neurosurgeons based on scientific indications. This descriptive-analytic study concerned patients referred to Emergency ward of Imam Reza Educational Hospital of Birjand, Birjand University of Medical Sciences during 2017. Ethical code was received by the Ethics Committee of the University (code Ir.bums.REC.1396.138).

\section{Inclusion criteria}

Patients older than 18 years of age with recent head blunt trauma (e.g., fall, driving accidents or others) within the last 24 hours, and GCS $\leq 13$ with abnormal CT scan.

\section{Exclusion criteria}

Patients under the age of 18 years, lack of single blunt head injury (including multiple trauma, penetrating lesions), no referral within the first 24 hours, and GCS $\geq 14$. Other exclusion criteria included history of anticoagulant drugs, pregnancy, underlying cerebral disease (brain tumors or ischemic and hemorrhagic lesions), lack of information or imaging, dissatisfaction.

\section{Clinical evaluation at referral and follow-up}

Vital signs were recorded at the time of arrival, 12 hours later, 24 hours later, as well as in the event of unstable state. Brain CT was performed in patients with an indication (after consulting neurosurgery) as emergency cases. All CT scan reports were based on both evaluation systems by radiologist. All surgical procedures and decisions about the clinical approach were performed by a surgeon. Then, the patients were followed up within two weeks from the beginning, the first month and the third month after referral, and the final status of the patients was determined at these intervals. The data were collected by a checklist based on the objectives of the plan.

\section{Statiscical analyses}

Data were entered into SPSS 22 software. In the descriptive section, information was classified and summarized using frequency tables and central indexes. At first, normal distribution of data was investigated by Kolmogorov-Smirnov test. The mean Mann-Whitney U test was appliedfor quantitative variables (two variables) at the significance level of $p \leq 0.05$. As matter of fact, this testcompare the means between the two groups with regard to normal distribution. Kruskal-wallis test was used to compare the quantitative variables. If the result was significant, the Mann-Whitney $U$ test was used to find a significant relationship.In order to examine the correlation of quantitative variables, with regard to the abnormal distribution of Spearman Correlation, a significant level of $p \leq 0.05$ was applied. To compare the predictive accuracy of the AUC curve, the binary logistic regression test was also used.

\section{Results and Discussion}

A total of 150 patients were enrolled in the study, $60 \%$ male and $40 \%$ female. The mean age of the patients was $43.36 \pm 21.65$ years and most of the patients were over 
Table 1. Frequency of type of brain injuries in patients under study

\begin{tabular}{lcc}
\hline Cerebral lesion & Frequency & Percent \\
\hline Mix & 33 & 22 \\
Epithelial hematoma & 30 & 20 \\
Subarachnoid hemorrhage & 30 & 20 \\
Intraventricular hemorrhage & 27 & 18 \\
Subdural hematoma & 14 & 9.4 \\
Cerebral contusion & 13 & 8.6 \\
Intraparenchymal hemorrhage & 3 & 2 \\
Total & 150 & 100 \\
\hline
\end{tabular}

Table 2. Frequency of Marshall Classification in patients

\begin{tabular}{lcc}
\hline Category & Frequency & Percent \\
\hline Diffuse injury II & 75 & 50 \\
Diffuse injury III (swelling) & 12 & 8 \\
Diffuse injury IV (shift) & 29 & 19.3 \\
\hline Evacuated mass lesion V & 29 & 19.3 \\
Non-evacuated mass lesion VI & 5 & 3.4 \\
Total & 150 & 100 \\
\hline
\end{tabular}

Table 3. Frequency of the Glasgow Outcome Scale in the next two weeks of referral (or discharge)

\begin{tabular}{lcc}
\hline Scale & Frequency & Percent \\
\hline Dead & 29 & 19.4 \\
Lower Severe Disability & 5 & 3.3 \\
Upper Severe Disability & 11 & 7.3 \\
Lower Moderate Disability & 29 & 19.3 \\
Upper Moderate Disability & 5 & 3.3 \\
Lower Good Recovery & 33 & 22 \\
Upper Good Recovery & 38 & 25.4 \\
Total & 150 & 100 \\
\hline
\end{tabular}

Table 4. Frequency of the Glasgow Outcome Scale one month later

\begin{tabular}{lcc}
\hline Scale & Frequency & Percent \\
\hline Dead & 30 & 20 \\
Lower Severe Disability & 0 & 0 \\
Upper Severe Disability & 3 & 1.4 \\
Lower Moderate Disability & 17 & 11.4 \\
Upper Moderate Disability & 5 & 3.5 \\
Lower Good Recovery & 49 & 32.9 \\
Upper Good Recovery & 46 & 30.8 \\
Total & 150 & 100 \\
\hline
\end{tabular}

50 years old ( 57 patients, $38 \%$ ). The mean GCS score was determined to be $8.7 \pm 3$ at the time of admission. In terms of severity of trauma, $52 \%$ of patients were belonged to severe traumatic brain (GCS3-8) and $49 \%$ of patientswere assigned to the moderate traumatic brain (GCS9-12) group.The study showed that most patients were referred due to road accidents (73 patients, $74.5 \%)$ and fall from height $(21,21.4 \%)$.In the next step, we presented the vital signs of the patients at the time of referral, after 12 and after 24 hours. The mean body temperature of the patients was determined as $36.9 \pm 2.3$ degrees Celsius at the time of admission, followed by the mean systolic blood pressure $(105.4 \pm 12.1 \mathrm{mmHg})$, mean diastolic blood pressure $(70.2 \pm 9.9 \mathrm{mmHg})$, mean heart rate $(96.82 \pm 18.12$ beats per minute), and mean respiratory rate $(13.89 \pm 3.1 \% \mathrm{~min})$. The mean body temperature of the patients was determined to be $36.7 \pm$ $0.3^{\circ} \mathrm{C}$ in 12 hours, following the mean systolic blood pressure of the patients $(107.77 \pm 11.53 \mathrm{mmHg})$, the mean diastolic blood pressure of the patients $(72.6 \pm 6.5$ $\mathrm{mmHg})$, mean heart rate of patients $(92.78 \pm 15.7$ beats per minute) and the mean respiratory rate $(13.7 \pm 6.8$ per 
Table 5. Frequency of The Glasgow Outcome Scale three months later

\begin{tabular}{lcc}
\hline Scale & Frequency & Percent \\
\hline Dead & 33 & 22 \\
Lower Severe Disability & 0 & 0 \\
Upper Severe Disability & 0 & 0 \\
Lower Moderate Disability & 8 & 5.4 \\
Upper Moderate Disability & 6 & 4 \\
Lower Good Recovery & 52 & 34.6 \\
Upper Good Recovery & 51 & 34 \\
Total & 150 & 100 \\
\hline
\end{tabular}

Table 6. Correlation between grades in Marshall Classification based on patient age

\begin{tabular}{lcc}
\hline Variable & Standard deviation \pm Mean & Spearman Test \\
\hline Age & $21.29 \pm 43.52$ & $=+0.334 \mathrm{r}$ \\
Marshall Classification Grid & $1.3 \pm 3.2$ & $=0.001 \mathrm{P}$ \\
\hline
\end{tabular}

Table 7. Correlation between Score in Rotterdam Classification and Age of Patients

\begin{tabular}{lcc}
\hline Variable & Standard deviation \pm Mean & Spearman Test \\
\hline Age & $21.29 \pm 43.52$ & $=+0.118 \mathrm{r}$ \\
Rotterdam Rating Score & $1.07 \pm 2.55$ & $=0.2 \mathrm{P}$ \\
\hline
\end{tabular}

Table 8. Comparison of mean GCS in terms of hematoma type

\begin{tabular}{lcccc}
\hline Cerebral lesion & $\begin{array}{c}\text { Standard deviation } \pm \\
\text { Mean }\end{array}$ & Middle & $95 \%$ CI & Kruskal-Wallis \\
\hline Mix & $3.1 \pm 8.85$ & 8.5 & $7.38-10.32$ & $=7.8 \mathrm{X}^{2}$ \\
Epithelial hematoma & $3.14 \pm 9.53$ & 11 & $7.9-11.15$ & $=0.2 \mathrm{P}$ \\
Subarachnoid Hemorrhage & $2.35 \pm 7.76$ & 7 & $6.55-8.98$ & \\
Intraventricular Hemorrhage & $3.27 \pm 7.20$ & 8 & $5.38-9.02$ & \\
Subdural hematoma & $3.26 \pm 8.79$ & 9 & $6.90-10.67$ & \\
Cerebral contusion & $9.46 \pm 2.47$ & 10 & $7.79-10.95$ & \\
Intraventricular hemorrhage & $7 \pm 2.82$ & 7 & $6.90-9.41$ & \\
\hline
\end{tabular}

Table 9. Comparison of grade average in Marshall Classification by type of hematoma

\begin{tabular}{lcccc}
\hline Cerebral lesion & $\begin{array}{c}\text { Standard deviation } \pm \\
\text { Mean }\end{array}$ & Middle & $95 \%$ CI & Kruskal-Wall \\
\hline Mix & $1.2 \pm 2.83$ & 2 & $2.24-3.43$ & $=10.7 \mathrm{X}^{2}$ \\
Epithelial hematoma & $1.32 \pm 3$ & 2 & $2.32-3.68$ & $=0.09 \mathrm{P}$ \\
Subarachnoid hemorrhage & $1.49 \pm 3.35$ & 3 & $2.58-4.12$ & \\
Intraventricular hemorrhage & $1.16 \pm 3.07$ & 3 & $2.42-3.71$ & \\
Subdural hematoma & $1.38 \pm 4.07$ & 5 & $3.27-4.87$ & \\
Cerebral contusion & $2.85 \pm 0.9$ & 2 & $2.25-3.44$ & \\
Intraventricular hemorrhage & $4.5 \pm 0.7$ & 4 & $3.38-4.95$ & \\
\hline
\end{tabular}

minute). The mean body temperature of the patients was recorded at $36.85 \pm 0.2{ }^{\circ} \mathrm{C}$ for 24 hours, followed by mean systolic blood pressure in the patients $(110.28 \pm 9.98$ $\mathrm{mmHg})$, mean diastolic blood pressure $(73.52 \pm 6.8$ $\mathrm{mmHg})$, mean heart rate of patients $(89.87 \pm 13.7$ beats per minute) and mean respiratory rate $(13.56 \pm 6.7$ breaths per minute). In examining the frequency distribution of traumatic brain injury, hematoma was most commonly mixed (20.4\%), followed by epidural hematoma (17.3\%), subarachnoid hemorrhage (17.3\%), and intraventricular hemorrhage $(15.3 \%)$ (Table 1). The mean scores of patients in the Marshall and Rotterdam classifications were determined as $3.2 \pm 1.3$ and $2.5 \pm 1.0$, respectively, and, most patients had Grade II in the Marshall Classification $(46,46.9 \%$ ) (Table 2). Based on The Glasgow Outcome Scale, the final outcome of the patients is presented in the second week (or the discharge time, one month later and three months later. Based on the Glasgow Outcome Scale, the final outcome of the patientsis presented in the second week or on discharge, one month later and three months later. The mortality rate was $19.4 \%$ (19 cases) during the second week (or at the 
Table 10. Comparison of mean score in Rotterdam classification according to hematoma type

\begin{tabular}{lcccr}
\hline Cerebral lesion & $\begin{array}{c}\text { Standard deviation } \pm \\
\text { Mean }\end{array}$ & Middle & $95 \%$ CI & Kruskal-Wa \\
\hline Mix & $1.13 \pm 2.85$ & 3 & $2.32-3.38$ & $=36.1 \mathrm{X}^{2}$ \\
Epithelial hematoma & $0.47 \pm 1.29$ & 1 & $1.05-1.54$ & $=0.001 \mathrm{P}$ \\
Subarachnoid Hemorrhage & $0.8 \pm 3.18$ & 3 & $2.76-3.59$ & \\
Intraventricular Hemorrhage & $1 \pm 3$ & 3 & $2.45 \pm 3.55$ & \\
Subdural hematoma & $0.6 \pm 2.64$ & 3 & $2.28-3.01$ & \\
Cerebral contusion & $2.23 \pm 1.09$ & 2 & $1.57-2.89$ & \\
\hline
\end{tabular}

Table 11. The mean of Marshall CT Classification and Rotterdam CT score in predicting patients mortality during two weeks by using logistic regression analysis.

\begin{tabular}{ccccc}
\hline Variable & Estimated (B) & $\begin{array}{c}\text { Standard } \\
\text { deviation }\end{array}$ & P- Value & OR \\
\hline Rotterdam Score & $-0 / 8$ & $0 / 28$ & $0 / 004$ & $0 / 45$ \\
Marshall Score & $-0 / 6$ & $0 / 35$ & $0 / 07$ & $0 / 54$ \\
\hline
\end{tabular}

Table 12: The mean of Marshall CT Classification and Rotterdam CT score in predicting patients mortality during one month by using logistic regression analysis.

\begin{tabular}{ccccc}
\hline Variable & Estimated (B) & $\begin{array}{c}\text { Standard } \\
\text { deviation }\end{array}$ & P- Value & OR \\
\hline Rotterdam Score & $-0 / 88$ & $0 / 28$ & $0 / 001$ & $0 / 41$ \\
Marshall Score & $-0 / 48$ & $0 / 34$ & $0 / 15$ & $0 / 62$ \\
\hline
\end{tabular}

Table 13: The mean of Marshall CT Classification and Rotterdam CT score in predicting patients' mortality during three month by using logistic regression analysis

\begin{tabular}{ccccc}
\hline Variable & Estimated (B) & $\begin{array}{c}\text { Standard } \\
\text { deviation }\end{array}$ & P- Value & OR \\
\hline Rotterdam Score & $-0 / 88$ & $0 / 27$ & $0 / 001$ & $0 / 41$ \\
Marshall Score & $-0 / 48$ & $0 / 33$ & $0 / 15$ & $0 / 62$ \\
\hline
\end{tabular}

time of discharge), regarding to GOS, most patients had a good return (71 patients, 47.4\%) (Table 3). The mortality rate was $20 \%$ one month after the submission. As expected, most patients returned based on GOS (95\%, $63.7 \%$ ) (Table 4). The mortality rate was also determined to be $22 \%$ and most patients had a good return based on GOS (103, 68.6\%) (Table 5). The correlation between age and GCS was performed using Spearman test. Results demonstrated that there was no relationship between these two variables $(r=0.98, r=0.008)$.

Also, there was a significant positive correlation between the mean score of the Marshall classification and the age of the patients, and patients with a higher mean age had higher grade Marshall Classification $(\mathrm{r}=0.334, \mathrm{p}=$ 0.001) (Table 6). There was no significant correlation between the mean scores in Rotterdam classification and the age of the patients $(\mathrm{p}=0.2, \mathrm{r}=0.11)$ (Table 7). The median and middle grades in the Marshall Classification were determined as 3 and $3.25 \pm 1.3$, respectively, while these values in female subjects were 2 and 3.14 \pm 1.2 , respectively. The observed difference was not statistically significant $(\mathrm{p}=0.7)$. Regarding the abnormal distribution of mean GCS, the Kruskal-Wallis test was applied to compare different types of hematoma, whereas there was no significant difference $(p=0.2)$, (Table 8$)$. Regarding the abnormal distribution of mean grade in Marshall Classification, Kruskal-Wallis test was used to compare different types of hematoma, which there was no significant difference $(p=0.09)$ (Table 9). With regard to the abnormal distribution of mean score in Rotterdam classification, Kruskal-Wallis test was used to compare different types of hematoma. However, No significant difference was found between hematoma types $(p=0.001)$. Therefore, the results of the MannWhitney test were examined. Based on the findings of this test, there was a significant difference between the mean score of Rotterdam in epidural hematoma and all types of hematomas, including subdural hematoma $(\mathrm{p}=$ 0.001), intraventricular hemorrhage $(\mathrm{p}=0.0001)$, subarachnoid hemorrhage $(\mathrm{p}=0.0001)$ and mixed hematoma $(\mathrm{P}=0.0001)$. Moreover, no significant difference was observed for intra-parenchymal hemorrhage and hemorrhagic contusion among the subgroups (Table 10). In the patients after two weeks, the mean GCS score at the time of referral in living and dead persons was determined to be $9.47 \pm 2.42$ and $4.79 \pm 2.79$ respectively, the median score of GCS was set at 10 and 

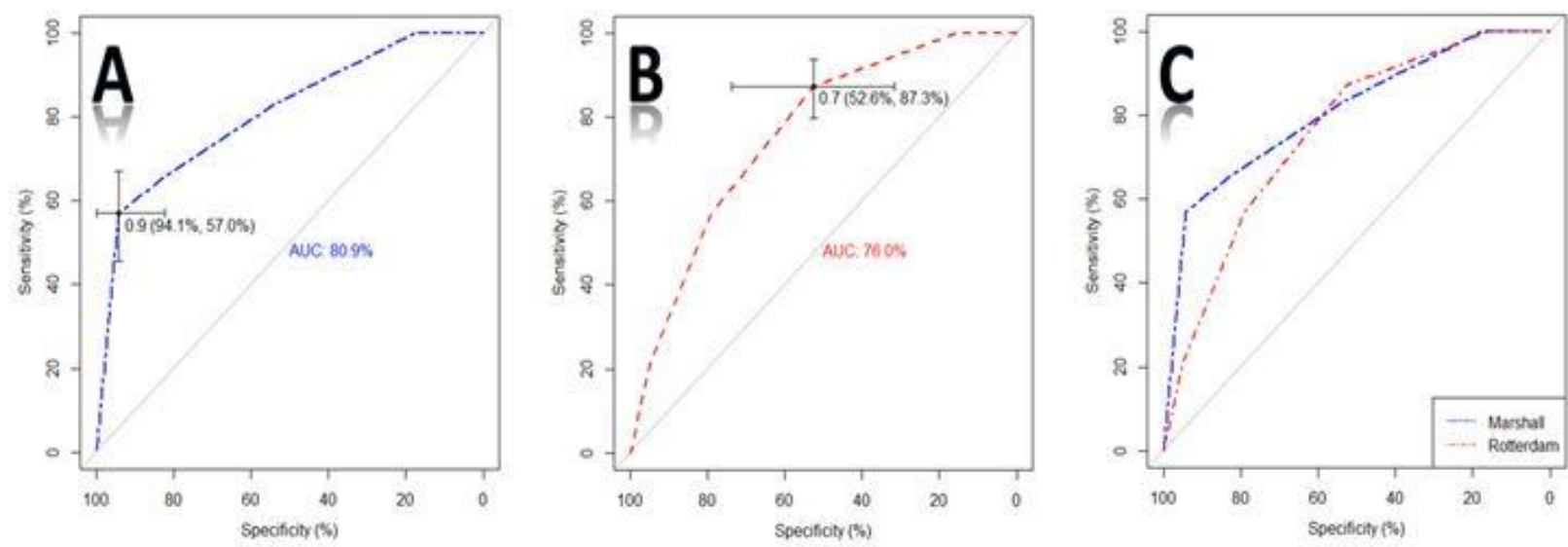

Fig 1. A: The rock curve for Rotterdam classification for prediction of mortality in the first two weeks, B: The Rock Curve for Marshall Classification in predicting mortality in the first two weeks, C: Comparison of Rock Curves (Marshall and Rotterdam Classifications) in the prognosis of mortality in the first two weeks.
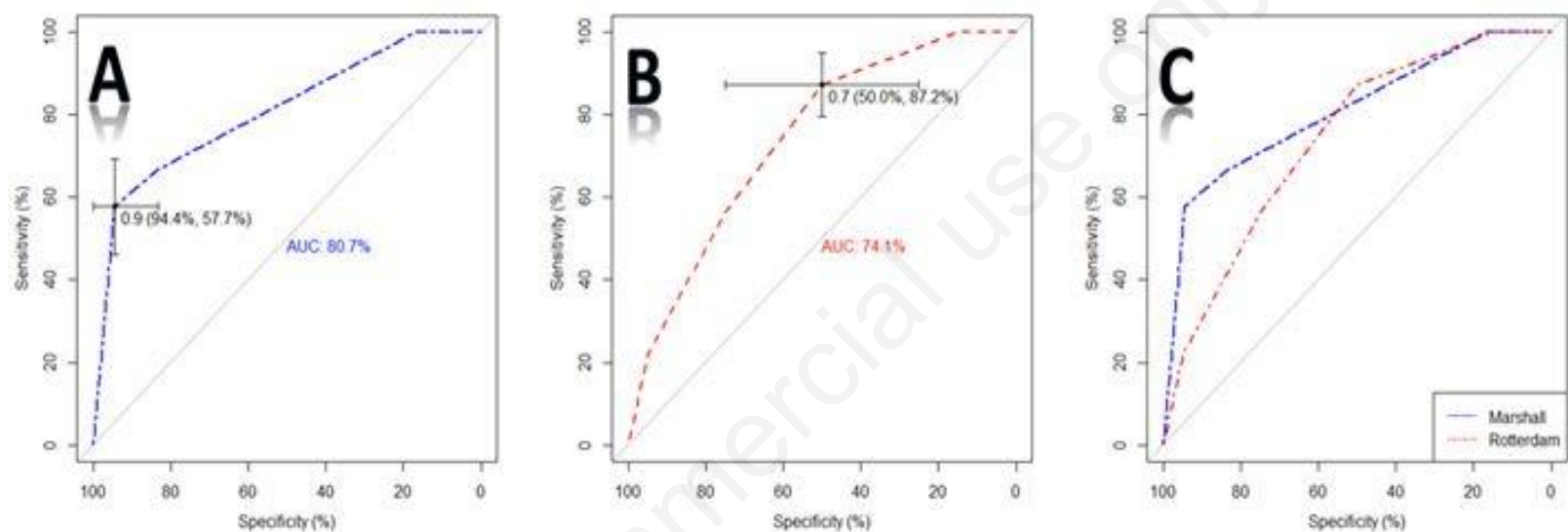

Fig 2 A: The rock curve for Rotterdam classification for prediction of mortality during the first month, B: The Rock Curve for Marshall Classification in predicting mortality during the first month, C: Comparison of Rock Curves (Marshall and Rotterdam Classifications) in the prognosis of mortality during the first month.
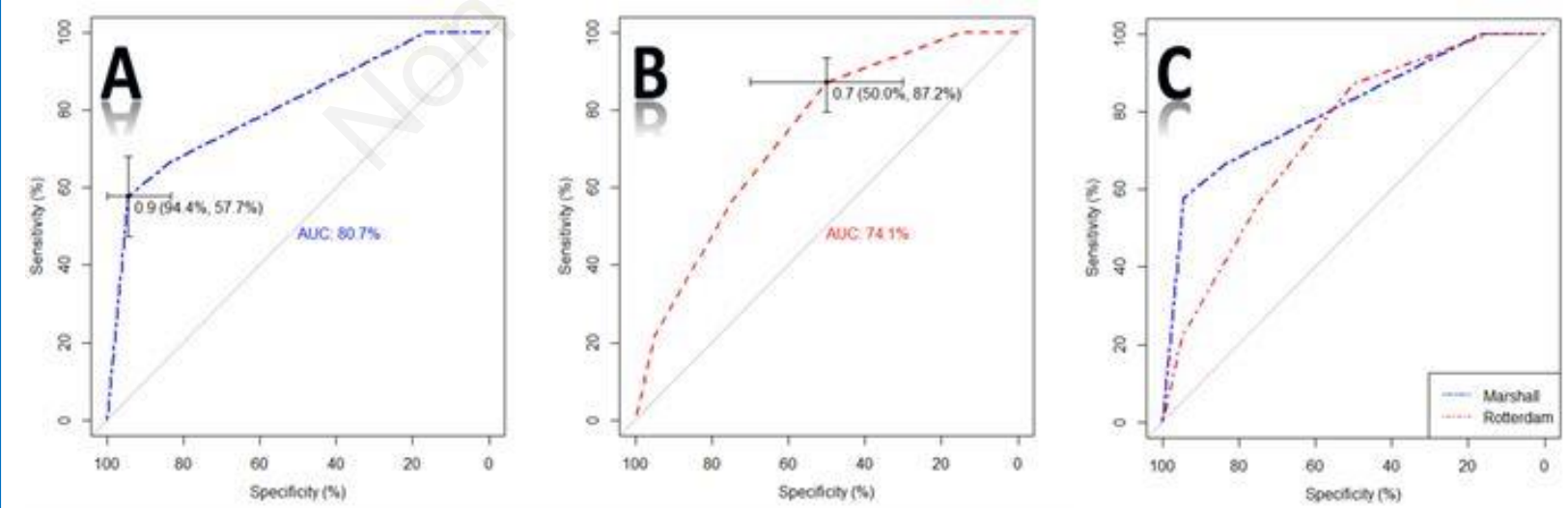

Fig 3. A: The rock curve for Rotterdam classification for prediction of mortality during three months, B: The Rock Curve for Marshall Classification in predicting mortality during three months, C: Comparison of Rock Curves (Marshall and Rotterdam Classifications) in the prognosis of mortality during three months

4 in live and dead individuals. The observed differences were statistically significant, subjects who died within two weeks had a significantly lower mean GCS score (p
$=0.0001$ and $\mathrm{Z}=5.8)$. In the patients after one month, the average GCS score at the referral time of living and dead persons was determined to be $9.53 \pm 2.38$ and $4.8 \pm$ 


\section{Marshall and Rotterdam CT scores}

Eur J Transl Myol 28 (3): 265-273, 2018

2.11, respectively. The mean score of GCS was also recorded as 10 and 4 , respectively, when referring to hospital among living and the dead persons. The observed differences were statistically significant. After one month, the dead persons had significantly lower average of GCS scores at admission time $(p=0.0001$ and $\mathrm{Z}=5.9$ ). After two weeks, the findings showed that the median and mean scores in the Marshall Classification in live patients were shown to be 2 and $2.95 \pm 1.2$, respectively, while these values were 4 and $4.41 \pm 1.12$, respectively $(\mathrm{P}=0.0001)$. Furthermore, after a month, the mean and mean scores in the Marshall Classification in live patients were 2 and $2.92 \pm 1.1$, respectively, and these values were recorded in 4 and $4.44 \pm 1$, respectively $(\mathrm{P}=$ 0.0001). After three months, the findings revealed that the median and mean scores in the Marshall Classification in live patients were 2 and $2.92 \pm 1.1$, respectively, while these values were determined as 4.44 and 1.44 in the dead population, respectively ( $\mathrm{p}=0.0001$ ). The median and mean scores in Rotterdam's classification after 2 weeks among live patients were calculated to be 2 and $2.34 \pm 0.9$, respectively. However, the dead patients showed that these values be 4 and $3.42 \pm 1.12(\mathrm{P}=0.0001)$, respectively. The median and mean scores in Rotterdam's classification after a month among live patients were calculated as 2 and $2.35 \pm 0.96$, respectively. Meanwhile, these values among the dead were determined to be 3 and 3.35 \pm 1.1 , respectively ( $\mathrm{P}=$ 0.001). After three months, our findings indicated that the median and mean scores in Rotterdam's classification were determined as 2 and $2.35 \pm 0.96$, respectively, and these values were also observed to be 3 and $3.35 \pm 1.1$, respectively $(\mathrm{P}=0.001)$. On the other hand, Rotterdam's score was significantly associated with patients' mortality in two weeks, after one month and also after three months ( $p=0.004, p=0.001, p=0.001)$. However, there was no significant correlation between Marshall Classification scores and patients mortality in these periods (Tables 11, 12 and 13). The sensitivity and specificity of Rotterdam's classification in predicting mortality in the second week were calculated as $56,94.11 \%$, respectively, and these values was determined to be $87.34 \%$ and $52.63 \%$, respectively for the Marshall Classification. The receiver operating characteristic (ROC) curve (AUC) is an indicator of the performance of the method used in study and a benchmark for comparing models. The more area under the curve represents a more accurate model and therefore provides a better model. AS a result, the classification of Rotterdam has a higher degree of accuracy (Fig. 1). The sensitivity and specificity of Rotterdam classification in predicting mortality in the first month was recorded as 57.69 and $94.44 \%$, respectively, while those for Marshall Classification were $87.17 \%$ and $50 \%$, respectively. The results indicate a higher accuracy of Rotterdam's classification in the prediction of mortality during the first month based on the ROC curve (Figure 2). Sensitivity and specificity of Rotterdam classification in predicting mortality in the third month was determined as 57.69, 94.44\%, respectively. While the values for the Marshall Classification was $87.17 \%$ and $50 \%$, respectively. Rotterdam's classification system has been more accurate than the Marshall Classification system to predict mortality within three months after the blunt head trauma based on the results of the ROC curve (Fig. 3). The aim of this study was to determine the predictive power of the initial outcome of patients based on Rotterdam and Marshall scoring in brain CT scans among patients with moderate to severe traumatic brain injury. The most important finding of this study was the higher accuracy of the Rotterdam classification system in comparison with the Marshall Classification System in predicting mortality in the first two weeks, the first month and the third month using the ROC curve. In multivariate analysis, only the Rotterdam scoring score significantly correlated with patient's mortality in two weeks, after a month, and after three months. Meanwhile, there was no significant correlation between Marshall Classification scores and patient mortality in the above-mentioned periods. The died patients had a lower GCS score at interval time in each of the two-week periods, one month and three months, while indicated higher grades for Rotterdam and Marshall classifications. Ppredictive potential of Rotterdam CT score was obtained in a multicenter clinical trial on the effect of tirilazad in the years 1994-1991 ${ }^{10}$. Its accuracy has been evaluated in various studies and AUCs (in the range of 0.76-0.68) have been reported with the same pseudo-R2 ${ }^{11,12}$. The Marshall Classification was based on the Traditional Coma Data Bank (TCDB) from 1987 to 1984, in which 746 patients with severe traumatic traumatic brain injury (GCS 3-8) compared with other classification systems that had the lowest pseudo- variance, adding it to the checklist for patients with traumatic brain injury in admission time does not provide any additional independent information to doctors ${ }^{13}$. Deepika et al. (2015) in a study compared the predictive power of mortality from TBI in both Marshall and Rotterdam scoring methods, the mean grade based on the Marshall Classification and Rotterdam classifications in died patients was significantly higher than that of the live patients ${ }^{14}$, which is in agreement with our study. However, the results of the current study Revealed that Rotterdam's classification system has a higher accuracy in predicting mortality, contrary to our study, Deepika et al. (2015) reported that there has been a good correlation between the results of two methods and predictive accuracy of Marshall and Rotterdam classification did not differ in determining primary mortality following a moderate to severe TBI ${ }^{14}$. Another study reported similar results. Mentioned study has been performed using CT scan findings to evaluate the outcome of patients with moderate to severe head trauma, where the findings showed that both Marshall and Rotterdam methods have been appropriate for predicting mortality. Furthermore, both the Marshall and Rotterdam classification methods 


\section{Marshall and Rotterdam CT scores}

Eur J Transl Myol 28 (3): 265-273, 2018

had the same predictive power, respectively ${ }^{5}$, which was not consistent with the results of the present study, because in the present study, the Rotterdam classification system was far more precise than the Marshall classification. Munakomi (2016) study also reported similar results to the present study. In this study, the Rotterdam-Marshall scoring method was evaluated for predicting the early outcome in patients with brain trauma. The results showed that the AUC of both classification systems was similar in predicting the early outcome in patients with brain trauma, the score of each of these systems has been related to the outcome of the patients ${ }^{15}$. In another study by Talari et al. (2016), the association between the prognosis of blunt head injury and Rotterdam criteria was investigated. The results of the study indicated that, the score of the Rotterdam system was one of the main factors predicting prognosis and was directly associated with the outcome of the patients ${ }^{16}$, which was in agreement with our study. A study by Liesemer et al. (2014) examined the prognosis of moderate-to-severe blunt head trauma in 600 patients using the Rotterdam classification. They have concluded that the most common class in the category was Rotterdam category 2, and these classification systems have had a good predictive value ${ }^{17}$. Regarding to the Marshall Classification, a study has also shown that a higher score of 5-6 is associated with greater mortality, while a score of 4-3 is associated with a higher craniotomy ${ }^{18}$. All of these studies have used a retrospective approach to examine two classification systems in evaluating the outcomes of patients with head trauma, and perhaps the reason for the observed difference between the present study and them is this issue regarding the continuity of the results and the similarity of the accuracy of the two methods. A study by Thelin et al. (2017) has compared several tools for evaluating patients with traumatic brain injury in examining the outcome of patients. Similarly, Thelin et al., Showed that the accuracy of Marshall CT classification was less than the classification of Rotterdam in examining the outcomes of patients with traumatic brain injury. Thelin and colleagues have been selected unfavorable outcomes to compare them with the tools, which suggest the possibility of using the Rotterdam system to evaluate morbidity, in addition to mortality ${ }^{13}$. In spite of the high accuracy of the Marshall and Rotterdam classification systems, especially the Rotterdam classification system, Maas et al. (2005) in a study using CT scan results of over 2500 patients with blunt trauma, has concluded that by adding some variables to these scoring systems, their performance can be improved ${ }^{7}$. The results of this study indicated a lower accuracy of the Marshall Classification System in predicting mortality, it is worth noting that this evaluation system has fundamental constraints, one of which is the worse prognosis of Grade IV than Grade V and VI. Another limitation of this classification system is the lack of attention to subarachnoid hemorrhage and the lack of consideration for the difference between epidural hematoma and subdural hematoma ${ }^{13}$. As previously mentioned, no additional independent information is provided to doctors ${ }^{13}$, if the Marshall Assessment System be added to the assessment checklist of patients with traumatic brain injury. Of course, today, MRI-based methods for assessing traumatic brain injury, especially its moderate and mild types, have been considered with greater accuracy and sensitivity ${ }^{19}$.

The most important finding of this study was the higher accuracy of Rotterdam's classification system as compared to the Marshall Classification System in predicting mortality in the first two weeks, first month and third month with ROC curve. Rotterdam score was significantly correlated with mortality of patients after two weeks, after a month, and also after three months, while there was no significant correlation between Marshall Classification scores with mortality of patients during the above-mentioned periods. The dead patients had a lower GCS score during the above-mentioned periods (two weeks, one month, and three months), while the ranking score for Rotterdam and Marshall has been higher.

\section{List of acronyms}

CT - Computed Tomography

TBI - Traumatic Brain Injury

EDH - Epidural Hematoma

SDH - Subdural Hematoma

GCS - Glasgow Coma Scale

TCDB - Traditional Coma Data Bank

ROC - Receiver Operating Characteristic

\section{Author's contributions}

Each author contributed in equal part to the manuscript.

\section{Acknowledgments \\ Funding: None.}

\section{Conflict of Interest}

The authors declare no conflicts of interests.

\section{Ethical Publication Statement}

We confirm that we have read the Journal's position on issues involved in ethical publication and affirm that this report is consistent with those guidelines.

\section{Corresponding Author}

Marzieh Haghparast, Department of Radiology, Birjand University of Medical Sciences, Birjand, Iran.

Phone: +989152650950

Email: Haghparast65m@yahoo.com

E-mail of co-authors

Mahyar Mohammadifard: Mahyarmohammadifard@yahoo.com

Kazem Ghaemi: Ghaemi@bums.ac.ir

Hamed Hanif: dr.hamed.hanif@gmail.com

Gholamreza Sharifzadeh: rezamood@yahoo.com 


\section{Marshall and Rotterdam CT scores}

Eur J Transl Myol 28 (3): 265-273, 2018

\section{References}

1. Maas AI, Stocchetti N, Bullock R. Moderate and severe traumatic brain injury in adults. The Lancet Neurology 2008;7:728-41.

2. Fajardo PL, Montenegro SL. Advances in the management of head injury. Emergencias 2009;21:433-40.

3. Karbakhsh M, Zandi N, Rouzrokh M, et al. Injury epidemiology in Kermanshah: the National Trauma Project in Islamic Republic of Iran. East Mediterr Health J 2009;15:57-64.

4. Bullock MR, Povlishock JT. Guidelines for the management of severe traumatic brain injury. Editor's Commentary. J Neurotrauma 2007;24 Suppl 1:2 p preceding S1.

5. Mata-Mbemba D, Mugikura S, Nakagawa A, et al. Early CT findings to predict early death in patients with traumatic brain injury: Marshall and Rotterdam CT scoring systems compared in the major academic tertiary care hospital in northeastern Japan. Acad Radiol 2014;21:605-11.

6. Marshall LF, Marshall SB, Klauber MR, et al. A new classification of head injury based on computerized tomography. Special Supplements 1991;75:S14-S20.

7. Maas AI, Hukkelhoven CW, Marshall LF, et al. Prediction of outcome in traumatic brain injury with computed tomographic characteristics: a comparison between the computed tomographic classification and combinations of computed tomographic predictors. Neurosurgery 2005;57:1173-82.

8. Chun KA, Manley GT, Stiver SI, et al. Interobserver variability in the assessment of CT imaging features of traumatic brain injur. J Neurotrauma 2010 ; 27: 325-30.

9. Hemmatim H, Chabok S, Dehnadimoghadam A, et al. An Epidemiologic Study of Trauma in Guilan (North of Iran). Acta Med Iran 2009;47:403-8.

10. Hukkelhoven CW, Steyerberg EW, Farace E, et al. Regional differences in patient characteristics, case management, and outcomes in traumatic brain injury: experience from the tirilazad trials. J Neurosurg 2002;97:549-57.

11. Nelson DW, Nystrom H, MacCallum RM, et al. Extended analysis of early computed tomography scans of traumatic brain injured patients and relations to outcome. J Neurotrauma 2010;27:5164.

12. Raj R, Siironen J, Skrifvars MB, et al. Predicting outcome in traumatic brain injury: development of a novel computerized tomography classification system (Helsinki computerized tomography score). Neurosurgery 2014;75:632-46

13. Thelin EP, Nelson DW, Vehviläinen $J$, et al. Evaluation of novel computerized tomography scoring systems in human traumatic brain injury: An observational, multicenter study. PLoS medicine 2017; 14:e1002368.

14. Deepika A, Prabhuraj AR, Saikia A, et al. Comparison of predictability of Marshall and Rotterdam CT scan scoring system in determining early mortality after traumatic brain injury. Acta Neurochir (Wien) 2015;157:2033-8.

15. Munakomi S. A comparative study between Marshall and Rotterdam CT scores in predicting early deaths in patients with traumatic brain injury in a major tertiary care hospital in Nepal. Chin $\mathbf{J}$ Traumatol 2016;19:25-7

16. Talari HR, Fakharian E, Mousavi N, et al. The Rotterdam Scoring System Can Be Used as an Independent Factor for Predicting Traumatic Brain Injury Outcomes. World Neurosurgery 2016;87:195-9.

17. Liesemer K, Riva-Cambrin J, Bennett KS, et al. Use of Rotterdam CT scores for mortality risk stratification in children with traumatic brain injury. Pediatric critical care medicine : a journal of the Society of Critical Care Medicine and the World Federation of Pediatric Intensive and Critical Care Societies 2014;15:554-62.

18. Faez DCdS. Análise da retirada da ventilação mecânica dos pacientes vítimas de traumatismo craniencefálico grave: Universidade de Campinas; 2016.

19. Zare Mehrjardi M, Darabi M, Bagheri SM, et al. The role of ultrasound (US) and magnetic resonance imaging (MRI) in penile fracture mapping for modified surgical repair. Int Urol Nephrol 2017;49:937-45.

Submission: May 06, 2018

Revision received: May 14, 2018

Acceptance: May 14, 2018 